\title{
A REDEMOCRATIZAÇÃO DO PERIODO MANGABEIRA (1945 A 1950) NA ESCOLA NORMAL DE FEIRA DE SANTANA: FORMAÇÃO DOCENTE E PROJETOS EDUCACIONAIS.
}

\author{
Luana Santos ${ }^{1} ;$ Ione Sousa ${ }^{2}$
}

1. Bolsista FAPESB, Graduanda em História, Universidade Estadual de Feira de Santana, e-mail: magalhaeslua@ @otmail.com

2. Orientadora, Departamento de Ciências Humanas e Filosofia, Universidade Estadual de Feira de Santana, e-mail:ionecjs@gmail.com

\section{PALAVRAS-CHAVE: ESCOLA NORMAL, FEIRA DE SANTANA, GOVERNO MANGABEIRA, IDEIAS PEDAGÓGICAS ANISIANAS.}

\section{INTRODUÇÃO}

A Escola Normal de Feira de Santana (ENFSA), fundada em 1927, enquanto instituição destinada à formação profissional de professoras para a região interiorana da Bahia, teve um papel fundamental na História da Educação feirense e de sua região (SOUSA, 2002).

O objetivo desta pesquisa é identificar se ocorreu a incorporação dos ideais pedagógicos anisianos nas propostas de formação de professoras na ENFSA, e se estes são visíveis em modificações curriculares e disciplinares, a partir dos registros desta instituição, entre 1945 a 1950, no contexto da redemocratização do Governo de Octavio Mangabeira e da gestão de Anísio Teixeira. Um segundo objetivo é buscar se estas ideias pedagógicos repercutiram na sociedade de forma mais ampla, sendo registradas no periódico Folha do Norte.

As reformas que propunham melhorias e ampliação das escolas primárias, assim como, a formação de professores e o aperfeiçoamento nos métodos de ensino, com a promulgação da Constituição Federal de 1946 - assegurando o direito a todos a educação -, era necessário levar a pratica esse ideário de educação. Com o regresso de Anísio a Educação Baiana em 1947 - agora como então Secretário da Educação, poderia fazer com que houvesse a partir do Estado um esforço para aplicar esses ideais.

\section{MATERIAL E METODOLOGIA}

Para trabalhar as fontes levantadas, como o material burocrático da Escola Normal: históricos escolares dos alunos, caderno de correspondência, livro de inventário, livros didáticos e diários de classe, utilizei a proposição de Bacelar:

\footnotetext{
"Usar luvas, máscara e avental no contato direto com os documentos; manusear os papéis com cuidado, respeitando seus limites [...]; manter os documentos guardados na ordem encontrada; assenhorear-se da caligrafia e das formas de escrita do material [...]; aprender e aprimorar-se em técnicas de levantamento, seleção e anotação do que é interessante e de registro das referências das fontes para futura citação; observar as regras existentes para transcrições e edições; anotar a referência do documento transcrito e indicar todos os dados que permitam identificá-lo; diferenciar com rigor o texto não copiado do texto cuja leitura foi impossível; se o documento for extenso, devem-se registrar as mudanças de página, indicando a numeração, quando existente, ou indicando a folha (frente e verso) em questão; trabalhar com número adequado de casos que garantam margem aceitável de segurança para fazer afirmações, especialmente de caráter quantitativo e generalizante; contextualizar o documento que se coleta (entender o texto no contexto de sua época, inclusive o significado das palavras e das expressões empregadas); estar atento às medidas utilizadas por quem produziu o documento,
} 
assim como a seus critérios, vieses e problemas de identificação de pessoas; cruzar fontes, cotejar informações, justapor documentos, relacionar texto e contexto, estabelecer constantes, identificar mudanças e permanências." (PINSKY, 2008. p. 72).

Quanto aos procedimentos na documentação geral do acervo no Instituto Educacional Gastão Guimarães (IEGG), parte das atividades da pesquisa, foi efetuada a identificação, triagem, higienização e limpeza dos documentos.

Com o jornal Folha do Norte, acessado na Casa do Sertão, foi feita a leitura e transcrição de notícias da Escola Normal de Feira de Santana e os decretos/leis referentes à instrução pública, utilizando a preposição de Luca:

\begin{abstract}
"Localizar a(s) publicação(ções) na história da imprensa. Atentar para as características de ordem material (periodicidade, impressão; papel, uso/ausência de iconografia e de publicidade). Assenhorar-se da forma de organização interna do conteúdo. Caracterizar o material iconográfico presente, atentando para as opções estéticas e funções cumpridas por ele na publicação. Caracterizar o grupo responsável pela publicação. Identificar os principais colaboradores. Identificar o público a que se destinava. Identificar as fontes de receita. Analisar todo o material de acordo com a problemática escolhida”. (PINSKY, 2008. p. 142).
\end{abstract}

\title{
RESULTADOS E DISCUSSÃO
}

Foi possível parcialmente observar algumas mudanças propostas por Teixeira, como construções de novas escolas municiais, Decreto de Lei $n^{\circ} 172$ de 28 de janeiro de 1947; padronização dos horários das aulas, fincando o $1^{\circ}$ turno das 08:00 horas as 11:45 e o $2^{\circ}$ turno das 13:00 horas as 16:45 com intervalos para o descanso das crianças, no turno matutino das 10:00 as 10:30 e no período vespertino das 15:00 as 15:30; aperfeiçoamento das práticas docentes a parti de estágios, com a determinação da pratica dos alunos do $5^{\circ}$ ano normal (ou $2^{\circ}$ pedagógico) nas Escolas Elementares, art. 19 do Decreto $\mathrm{n}^{\circ} 11.234$, de 25 de fevereiro de 1939; significativo aumento no quadro de professores da Escola Normal.

Foi possível também, compreender uma parte do currículo da escola, fazendo parte dessa Geografia Geral e do Brasil; Psicologia; Pedagogia; História de Educação; Higiene, Puericultura e Educação Sanitária; Frances; Inglês; Educação Física, Trabalhos Manuais, Música e Canto Orfeônico; Estatística e Administração Escolar; Metodologia Geral e Especial; Desenho; Artes Industriais; e Latim. Todos nem sempre contando com professores catedráticos, isso é perceptível durante todos os registro da escola, que sempre solicita professor(a) para ocupar tais cadeiras. Na maioria das vezes o professor(a) catedrático encontrasse de licença. Também não foi possível estabelecer em quais series/ano tais "disciplinas" seriam ministradas e nem a carga horaria de cada uma.

É importante destacar a questões orçamentarias, que representou uma interferência na cultura escolar nos anos de 1945 e 1946. Observa-se no jornal Folha do Norte, constantes decretos reduzindo o orçamento para à educação baiana, no cruzamento com as informações dos cadernos de correspondências é expressivo o número de solicitações de verbas ao Tesouro do Estado, o pagamento de duodécimo de meses atrasados e pedidos de materiais de ensino e de escritórios. A partir do ano de 1947, tais solicitações diminuem significativamente, não havendo mais registro no jornal de decretos com o mesmo conteúdo dos anos anteriores.

Se faz necessário salientar que nos anos de 1947, 1948 e 1949 a um aumento no número de chamadas nos jornal Folha do Norte referente a campanha contra a analfabetismo, muito expressivo. E que no ano de 1948 houve o envio de um questionário, proveniente do Instituto de Estudos Pedagógicos do Ministério da Educação, respondido pela/os alunas/os Tais ações podem ter ocorrido por uma iniciativa da Secretaria de Educação e Saúde da 
Bahia, como forma de alcançar as metas de governo de Octavio Mangabeira e Anísio Teixeira.

\section{CONSIDERAÇÕES FINAIS}

A pesquisa encontra-se finalizado, porém não concluído, por conta da limitação do acesso aos arquivos burocráticos do ENFS - que se encontram em poder do IEGG - bem como, dos arquivos de Octavio Mangabeira em poder do Arquivo Público e as dificuldades em conseguir encontrar os projetos de reforma da instrução após o ano de 1930.

Nesse período, foi possível compreender que o pensamento anisiano foi concretizado, em partes, na cidade de Feira de Santana. Pois, a partir de 1947 mudanças significativas acontecem no cotidiano da Escola Normal e na sociedade, como foi expostos nos resultados, houve o aumento de professores na Escola Normal; designação de professores para escolas distritais; novas construções ligadas a educação dos jovens (escolas e o ginásio oficial). Contudo, houve o registrado de alunas que sofreram com atitudes antipedagógicas das professoras das escolas anexas e inúmeros registro solicitando professores para ocupar as cadeiras que se encontravam com seus catedráticos afastados dos exercícios. Essas ultimas observações me fizeram questionar como estavam sendo ministradas tais aulas, sendo essas ministradas por professores que não eram catedráticos para tal, bem como, quais conteúdos estavam sendo ministrados, pois as alunas acusam as professoras de terem desmerecidos seus conhecimentos.

\section{REFERENCIAS}

LIMA, Aruã Silva de. UMA DEMOCRACIA CONTRA O POVO: Juraci Magalhães, Otávio Mangabeira e a UDN na Bahia (1927 - 1946). Dissertação (Mestrado em História) Universidade Estadual de Feira de Santana, Feira de Santana, 2009.

PINSKY, Carla Bassanezi. Fontes históricas. São Paulo: Contexto, 2005.

SCHWARTZMAN, Simon (org.) Tempos de Capanema. São Paulo, Paz e Terra/Edusp. 1984

SOUSA, Ione Celeste de. Garotas tricolores, deusas fardadas: as normalistas em Feira de Santana. Bahia, 1925/45. SP: EDUC/PUC-SP; 2002.

Fontes bibliográficas

TEIXEIRA, Anísio. Relatório apresentado ao Ex. Sr. Cons. Bráulio Xavier da Silva Pereira, Secretário do Interior, Justiça e Instrução Pública, pelo Diretor Geral da Instrução Pública, para ser encaminhado ao governador do Estado da Bahia. Salvador, Imprensa Oficial do Estado, 1928. 123p.

TEIXEIRA, Anísio.

Relatório do Dr. Anísio Teixeira, Secretário de Educação e Saúde, do Estado. Educação, saúd e e assistencia no Estado da Bahia em 1948. Salvador, 1949. 80 p.

FILHO, Luiz Viana. Octávio Mangabeira: um homem na tempestade. Senado Federal, Centro Gráfico, $1986 . \quad$ Brasília $\quad$ Disponível em <http://www2.senado.leg.br/bdsf/item/id/91415> Acessado em 15 fev. 2015.

Decreto Lei 1.846, de 14/08/1925, Assembleia Legislativa do estado da Bahia.

Fontes Arquivísticas:

Livros de correspondência da ENFS, 1945/50. Jornal Folha do Norte, 1945/50 